\title{
Malaria in the State of Amazonas: a typical Brazilian tropical disease influenced by waves of economic development
}

\author{
Vanderson Souza Sampaio ${ }^{[1],[2],[3]}$, André Machado Siqueira ${ }^{[4],}$ \\ Maria das Graças Costa Alecrim ${ }^{[1],[2], ~ M a r i a ~ P a u l a ~ G o m e s ~ M o u r a ̃ o ~}{ }^{[1],[2],}$ \\ Paola Barbosa Marchesini ${ }^{[5]}$, Bernardino Cláudio Albuquerque ${ }^{[3]}$, Joabi Nascimento ${ }^{[1],[2]}$, \\ Élder Augusto Guimarães Figueira ${ }^{[3]}$, Wilson Duarte Alecrim ${ }^{[1]}$, \\ Wuelton Marcelo Monteiro ${ }^{[1],[2]}$ and Marcus Vinícius Guimarães Lacerda ${ }^{[1],[2],[6]}$
}

[1]. Fundação de Medicina Tropical Dr. Heitor Vieira Dourado, Manaus, AM. [2]. Universidade do Estado do Amazonas, Manaus, AM. [3]. Fundação de Vigilância em Saúde do Amazonas, Manaus, AM. [4]. Instituto Nacional de Infectologia Evandro Chagas, Fundação Oswaldo Cruz, Rio de Janeiro, RJ. [5]. Coordenação Nacional do Programa de Malária, Ministério da Saúde, Brasília, DF. [6]. Instituto de Pesquisa Leônidas \& Maria Deane, Fundação Oswaldo Cruz, Manaus, AM.

\begin{abstract}
In Brazil, more than $99 \%$ of malaria cases are reported in the Amazon, and the State of Amazonas accounts for $40 \%$ of this total. However, the accumulated experience and challenges in controlling malaria in this region in recent decades have not been reported. Throughout the first economic cycle during the rubber boom (1879 to 1912), malaria was recorded in the entire state, with the highest incidence in the villages near the Madeira River in the Southern part of the State of Amazonas. In the 1970s, during the second economic development cycle, the economy turned to the industrial sector and demanded a large labor force, resulting in a large migratory influx to the capital Manaus. Over time, a gradual increase in malaria transmission was observed in peri-urban areas. In the 1990s, the stimulation of agroforestry, particularly fish farming, led to the formation of permanent Anopheline breeding sites and increased malaria in settlements. The estimation of environmental impacts and the planning of measures to mitigate them, as seen in the construction of the Coari-Manaus gas pipeline, proved effective. Considering the changes occurred since the Amsterdam Conference in 1992, disease control has been based on early diagnosis and treatment, but the development of parasites that are resistant to major antimalarial drugs in Brazilian Amazon has posed a new challenge. Despite the decreased lethality and the gradual decrease in the number of malaria cases, disease elimination, which should be associated with government programs for economic development in the region, continues to be a challenge.
\end{abstract}

Keywords: Malaria. Epidemiology. Surveillance. Amazon.

\section{INTRODUCTION}

Malaria is considered one of the most important parasitic diseases, and it is responsible for approximately 216 million cases and 655,000 deaths annually worldwide ${ }^{(1)}$. Over the last 12 years, an average of 422,858 cases have been reported annually in Brazil, but although it is estimated that approximately $6,000,000$ cases occurred annually in the $1940 \mathrm{~s}^{(2)(3)}$. Currently, $99.7 \%$ of malaria cases are reported in the Amazon region, and the State of Amazonas accounts for $40 \%$ of this total ${ }^{(2)}$. The State of Amazonas is the largest federal unit of the Brazilian territory, with an area of $1,570,745.680 \mathrm{~km}^{2}$. It consists of low altitude topography and an equatorial climate and has high temperatures and high rainfall. The phenomena known as El Niño and La Niña

Corresponding author: Dr. Marcus Vinícius Guimarães de Lacerda. Diretoria de Ensino e Pesquisa/Fundação de Medicina Tropical Dr. Heitor Vieira Dourado. Avenida Pedro Teixeira 25, Dom Pedro, 69040-000 Manaus, AM, Brasil.

Phone: 5592 2127-3430

e-mail: marcuslacerda.br@gmail.com

Received 18 November 2014

Accepted 3 March 2015 are responsible for variations in weather patterns in the Amazon region $^{(4)(5)}$. The vegetation consists predominantly of upland forests, floodplains, and flooded forests. The state territory is bordered by the Amazon basin, to which the Amazon River is the main contributor ${ }^{(6)}$. In addition, $98 \%$ of the Amazonas territory is preserved, $23.5 \%$ is legally protected by conservation units, and the state ranks first in the conservation of native forests in Brazil $^{(7)}$. These environmental characteristics, combined with anthropogenic changes, and cultural, social, and climatic factors, are conducive to the formation of Anopheline breeding sites that promote the maintenance of endemic malaria ${ }^{(8)(9)}$. The influence of the environment on malarial transmission can be observed in the seasonal epidemiological profile, which is characterized by higher transmission intensity from the beginning of the dry season in June until the ebb period in October, when temporary breeding sites form on the river margins (Figure 1).

\section{THE HISTORY OF MALARIA IN THE AMAZON}

The first development cycle (rubber cycle)

The history of malaria in the Amazon is associated with important regional development projects and migrations. Initially, the most significant migration occurred during the 


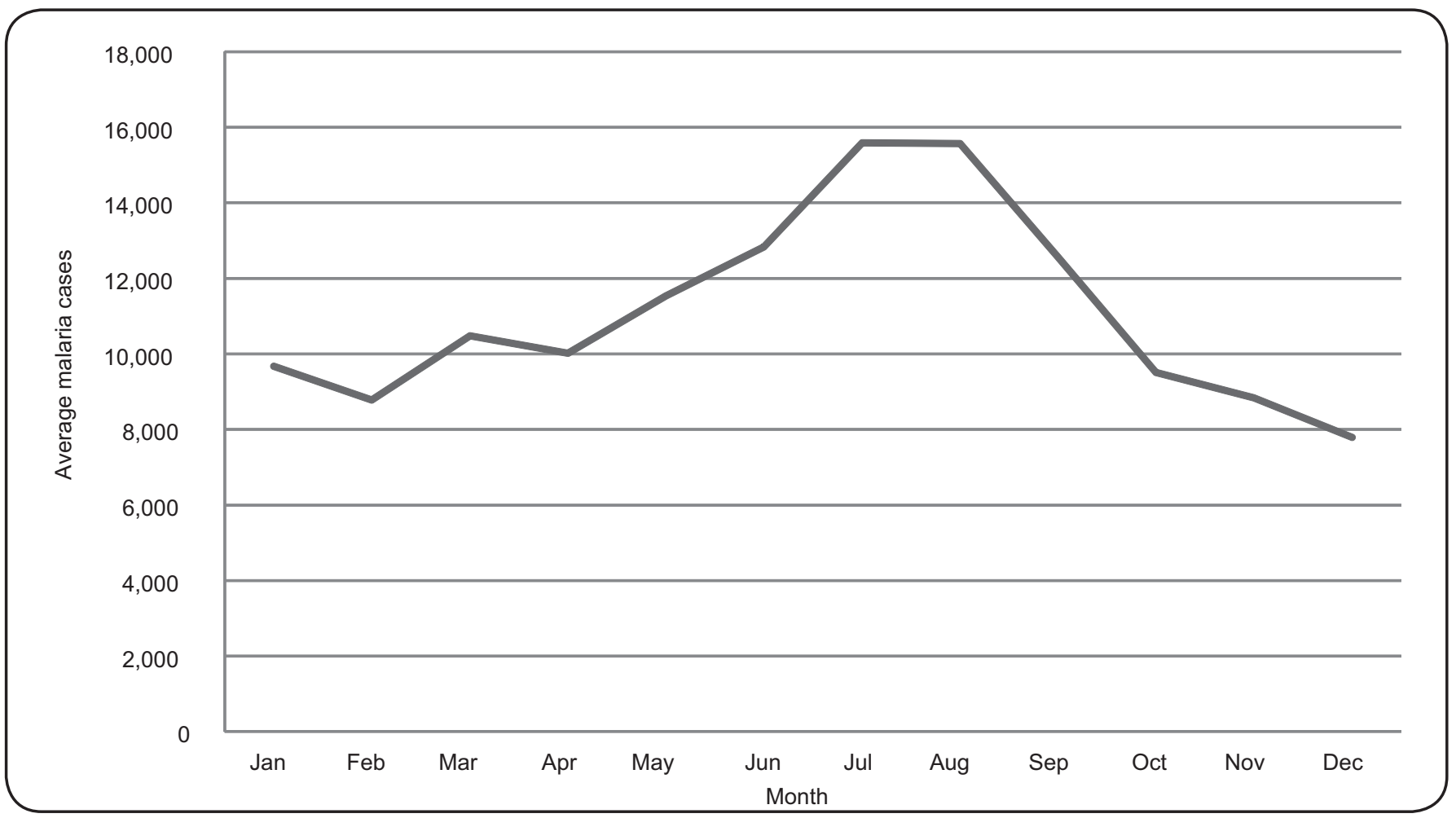

FIGURE 1 - Average annual cases of malaria by month in the State of Amazonas between 1962 and 2012.

rubber cycle (1879-1912). The rubber cycle represented the first development cycle in Amazonas and was stimulated by the global industrialization process in the late $19^{\text {th }}$ century when the industrial sector required rubber for the manufacture of car tires. At the end of this cycle, the construction of Fordlândia began on the banks of the Tapajós River, more than $1,000 \mathrm{~km}$ from Belém, to supply the American Ford Motor Company with the latex required to manufacture tires. The low productivity of rubber plantations in the region due to pests, in addition to public health problems such as malaria, promoted the disintegration of the enterprise ${ }^{(10)}$.

During the rubber cycle in the region, malaria cases were recorded in nearly the entire state, indicating the geographic spread of the disease. The incidence of malaria was higher in the villages near the Madeira River (southern region of the State of Amazonas), where immigrants were concentrated for latex extraction and forest clearing for the construction of the Madeira-Mamoré railroad. High fatality rates were reported for specific periods, such as in São Felipe (currently Eirunepé), where an epidemic during the first half of 1911 decimated $48 \%(411 / 850)$ of the population ${ }^{(10)}$. Even considering the low transmission compared with the rate in the state's southern region, the obituaries in Manaus indicated that malaria was the third most common cause of death in $1885^{(11)(12)}$. In 1900 , malaria was already the leading cause of death in Manaus according to official obituaries, with a fatality rate of $77 \%(1,945 / 2,516)^{(11)}$. This profile was maintained until the beginning of the economic crisis caused by the decline in the rubber cycle (Figure 2), which, to a large extent, was due to the increased cultivation of rubber trees in Malaysia ${ }^{(13)}$. During this period, the already small population of Amazonas decreased by more than $30 \%$.

After 1922, with the creation of the Department of Rural Sanitation and Prophylaxis [Diretoria de Saneamento e Profilaxia Rural (DSPR)], a significant and steady decrease in the incidence of malaria began. Prophylaxis with quinine and sanitation programs had positive effects on disease control until the early 1940s, when a new rubber cycle was promoted by the federal government due to a strong demand for rubber during World War II ${ }^{(11)(12)}$. During this period, malaria once again became one of the most prevalent diseases in the region. In Manaus, highly lethal outbreaks were reported until the early 1940s (Figure 2). After the end of World War II in 1945, the demand for rubber from Brazil decreased, and consequently, migration and malaria transmission also decreased ${ }^{(14)}$.

\section{The second development cycle}

Between the 1940s and 1960s, malaria transmission was not reported systematically, creating an information gap during this period and jeopardizing a more comprehensive temporal analysis. In 1962, improvements were made in the registration of malaria cases, and they started to be documented in management reports.

In the second half of the 1960s, during the military regime, the migration process intensified in the region. Road connections were made between Pará and Rondônia and the rest of the country, and therefore, these two areas were the most affected 


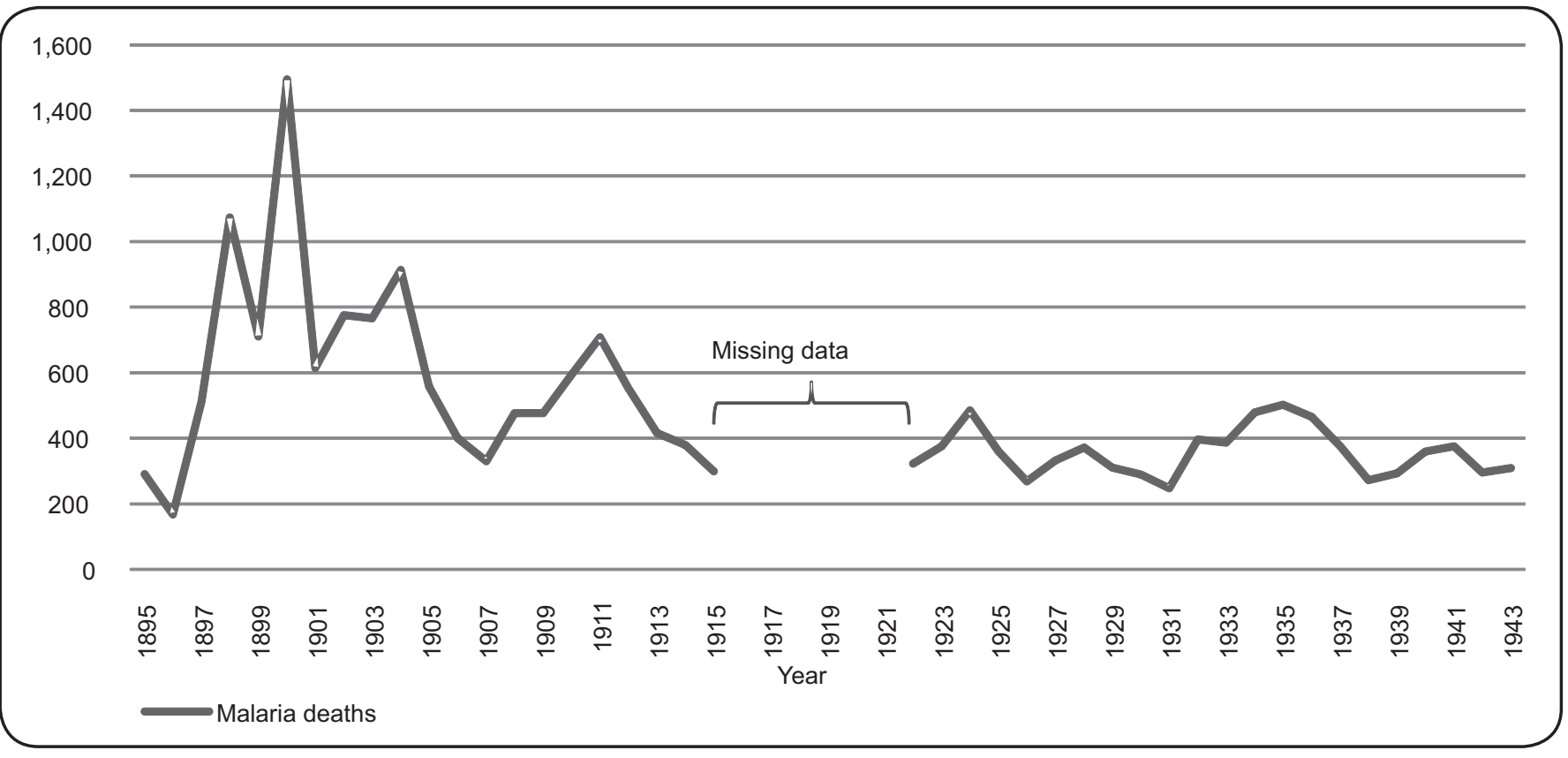

FIGURE 2 - Historical series of malaria deaths in Manaus between 1895 and 1943.

by the migratory influx and subsequent alterations to the natural environment. During this period, the construction of large federal highways was initiated, including BR-174 (ManausBoa Vista), BR-319 (Manaus-Porto Velho), and BR-230 (Trans-Amazon highway), attracting a large number of migrants and increasing the migratory flow to the remaining regions of the country. Malaria was a significant health problem among the inhabitants of the margin of the Trans-Amazon highway. Infections by Plasmodium falciparum were more frequent than those by Plasmodium vivax ${ }^{(15)}$.

Concurrent with the investment in highway construction to colonize the Amazon, the encouragement of the economic model known as the Free Economic Zone, established in Manaus [Zona Franca de Manaus (ZFM)] in the 1970s, attracted multinational companies, particularly from the electronics sector, to the region because of tax exemptions. Therefore, Manaus needed a larger labor force, and this demand triggered a new migratory flow from the interior of Amazonas and from other states located in the north and northeast regions of Brazil. This time, migrants moved to the city peripheries in a precarious and uncontrolled manner ${ }^{(16)}$. Consequently, there was a gradual increase in malaria transmission in peri-urban areas (Figure 3), which has persisted to date ${ }^{(17)}$. This period coincided with the success achieved by the Malaria Eradication Campaign [Campanha de Erradicação da Malária (CEM)] in the 1950s and 1960s in the Extra-Amazon region, which helped to limit the disease to the Amazonian Region, and consequently, the disease lost its political relevance in the national agenda ${ }^{(18)}$.

With the growing demand for electricity in the ZFM, the construction of a hydroelectric plant in Balbina in 1989, 150km from Manaus, was not followed by an increase in the number of malaria cases in the area due to preparations for the impact of construction ${ }^{(19)}$; this strategy was informed by the failure to control disease during the construction of the Tucuruí plant in the State of Pará in $1984^{(20)}$.

\section{The third development cycle}

In the 1990s, a new economic cycle began with the goal of strengthening the state's economy. This cycle involved the stimulation of agroforestry activities, particularly fish farming, which led to the formation of permanent Anopheline breeding sites $^{(21)(22)}$. Municipalities that engaged in agribusiness-based economic activities started to contribute to the export of malaria cases to Manaus, as observed by the increased number of malaria cases after holidays or regional festivities in the capital when a large proportion of the population from Manaus travelled to surrounding municipalities (Figure 4).

The remarkable oscillation in the transmission levels over time emphasizes the lack of sustainable control actions in the state (Figure 3). In fact, major development projects in the Amazon significantly influenced the hyperendemic conditions identified in some regions. Nonetheless, some conditions associated with the control programs also impacted this profile.

Newer projects, such as the Coari-Manaus pipeline that was initiated in July 2006 with the aim of transporting natural gas from the Urucu River Basin (tributary of the middle Solimões River) to Manaus, have taken into consideration environmental health aspects since their inception. An increase in the number of malaria cases was not observed in the areas of influence of these projects, suggesting that economic development in the region, when planned properly, did not promote malaria transmission ${ }^{(23)}$. 


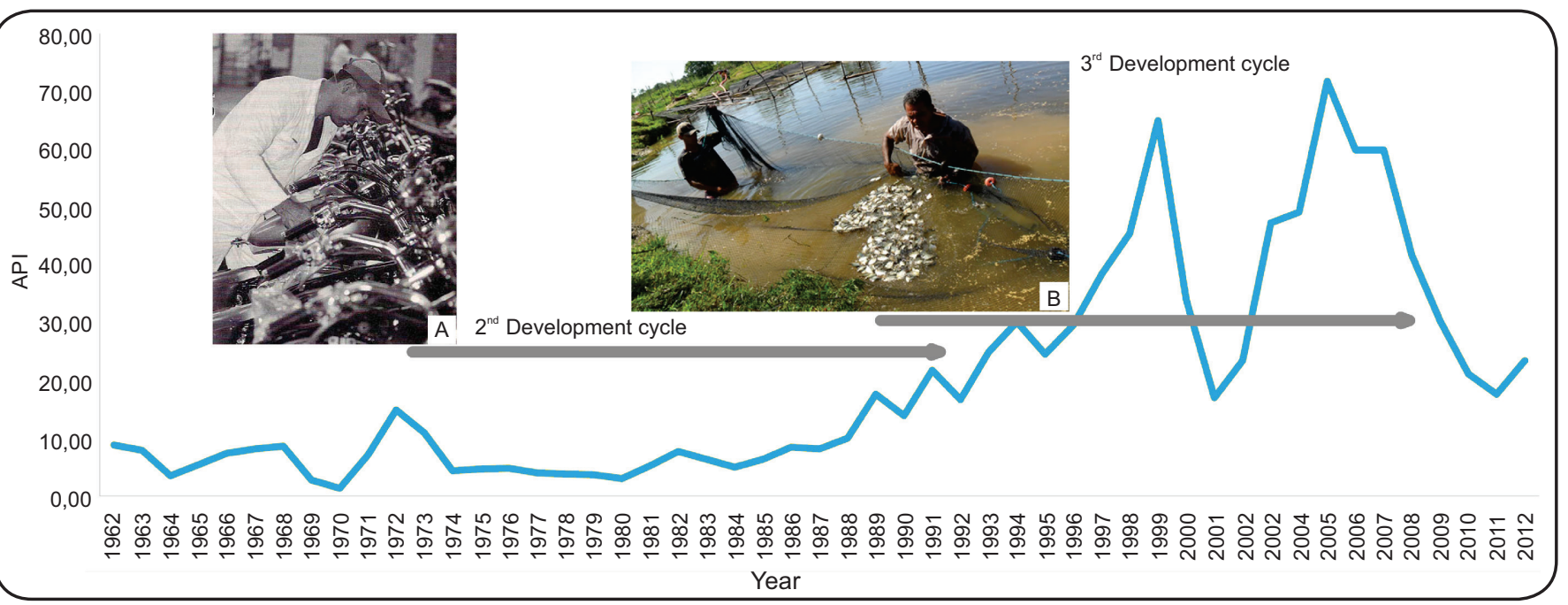

FIGURE 3 - Historical series of malaria cases (1962 to 2012) and contributing factors for disease spread in the Amazon. A: Factory worker in the production line for Honda in the Industrial District of Manaus in the 1970s. B: Rural worker harvesting fish from farming ponds. Sources: A: Documentation and Memory Center of 'Maurício Grabois Foundation' (Centro de Documentação e Memória Fundação Maurício Grabois; www.grabois.org). B: Portal Amazônia (www.portalamazonia.com.br). API: annual parasite index.

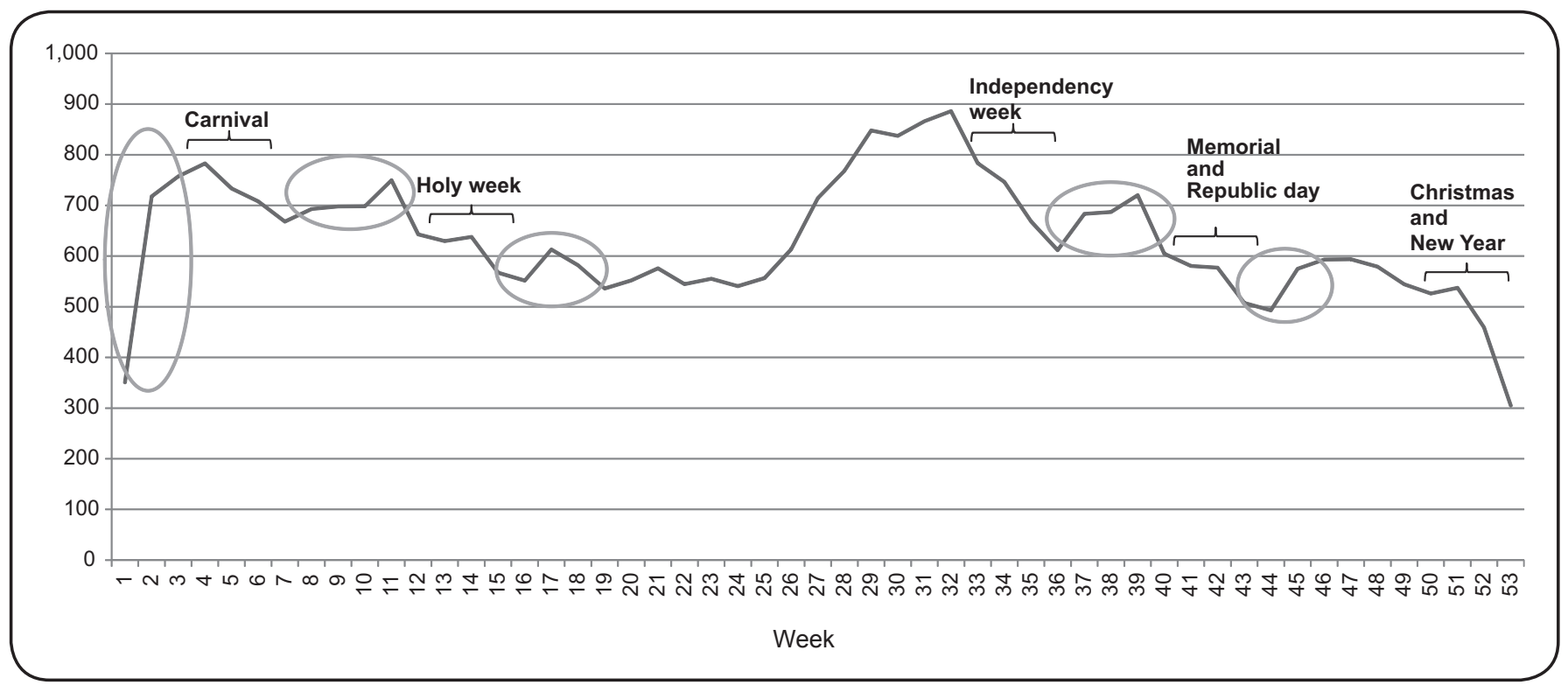

FIGURE 4 - Average annual malaria cases by epidemiological week in Manaus between 2003 and 2012, showing the infection peaks associated with the holidays.

\section{Epidemiological surveillance and control}

In Amazonas, systematic and institutionalized actions for malaria control began in the 1920 s with the creation of the DSPR. In the early 1940s, the Special Public Health Service [Serviço Especial de Saúde Pública (SESP)] and the National Malaria Service [Serviço Nacional de Malária (SNM)] were responsible for the control actions in the Amazon and ExtraAmazonian region, respectively. Only in the 1950s did the SNM start operating in the Amazon region. In 1960, the
Special Public Health Service became a Public Foundation (SESP Foundation) linked to the Ministry of Health ${ }^{(24)}$. In the late 1980s, state initiatives in Pará (Endemic System, 1989) and Rondônia (Malaria System, 1990) created the first computerized surveillance systems, replacing the technical reports that had been the only sources of epidemiological data. The difficulty in organizing and integrating these systems was the primary limitation to malaria surveillance.

In 1996, the Ministry of Health launched the Information System of the National Malaria Control Program [Sistema de 
Informações do Programa Nacional de Controle da Malária (SISMAL)]. At that time, all the Amazonian states started to report malaria cases using this system. In 2002, the Information System for Epidemiological Surveillance of Malaria [Sistema de Informação de Vigilância Epidemiológica da Malária (SIVEP)] was developed, allowing for a more integrated surveillance ${ }^{(23)}$.

Considering the increasing number of notifications of infectious disease cases in Manaus in 1970, with an emphasis on a malaria epidemic in the neighborhood of Alvorada (formerly called Cidade das Palhas), the physicians Heitor Vieira Dourado and Carlos Borborema, who were professors at the University of Amazonas, initiated the construction of a medical care and hospitalization facility in the region, the Tropical Medicine Foundation Dr. Heitor Vieira Dourado [Fundação de Medicina Tropical Dr. Heitor Vieira Dourado (FMT-HVD)]. This institution later became the benchmark for the treatment of other tropical diseases in Amazonas. The creation of the institution coincided with the onset of clinical malaria research in the state, contributing to the characterization of resistance to antimalarial drugs and to the co-development of novel drugs. Currently, the institution accounts for approximately $30 \%$ of the disease notifications in Manaus.

In 1999, the Ministry of Health launched the Plan for Intensification of Malaria Control Actions [Plano de Intensificação das Ações de Controle de Malária (PIACM)] as a response to the World Health Organization (WHO) Roll Back Malaria Program; this plan sought to contain the spread and limit the increase of the disease in the Amazon because that year registered the highest number of malaria cases ${ }^{(25)}$. In Amazonas, the process of health surveillance decentralization began only in 2001, when the control of endemic diseases was transferred to the coordination of the Department of Health of the State of Amazonas [Secretaria de Saúde do Estado do Amazonas (SUSAM)]. In 2005, the State of Amazonas Health Surveillance Foundation [Fundação de Vigilância em Saúde (FVS)] do Amazonas was created, and FVS began to consolidate all aspects of health surveillance within the state in a pioneer initiative among state surveillance systems. Since then, FVS, influenced by technical expertise from the Ministry of Health, has been responsible for the decentralization process at the municipal level. In 2013, through Ordinance 3,039 of the Ministry of Health, decentralization at the municipal level occurred in 62 municipalities of the State of Amazonas, as well as in other states of this region. One of the motivations for the decentralization process was the complex logistics required due to the extensive territory of Amazonas. Therefore, the technical and logistical planning of malaria control started to consider the geographical characteristics shared by the municipalities that depended on the same drainage basin ${ }^{(26)}$. Through the National Program for Malaria Control [Programa Nacional de Controle de Malária (PNCM)], the Ministry of Health encouraged the strengthening of local management and provided technical support for the implementation of the Project for the Prevention and Control of Malaria in the Brazilian Amazon. This project was financed by the Global Fund to Fight AIDS, Tuberculosis, and Malaria (2010/2012) and provided increased access to long-lasting insecticidal nets (LLINs), conventional and rapid diagnostic tests, and health education. Furthermore, the ministry strengthened the employment and training of technical staff in priority municipalities. Six States of the Legal Amazon, specifically Acre, Amapá, Amazonas, Pará, Rondônia, and Roraima, were covered by this initiative, which resulted in a $50 \%$ decrease in the number of malaria cases. However, the State of Amazonas had already implemented the Multiannual Action Plan for Malaria Control 2007-2010 (Plano Plurianual das Ações de Controle de Malária (PPACM), 2007-2010) in 2007, which was coordinated by FVS. Despite FVS efforts, much remains to be done because the State of Amazonas still ranks among the three states with the highest incidence of malaria reports.

The PPACM aimed at a sustainable decrease in the number of malaria cases via the technical strengthening of municipalities and by encouraging the decentralization of surveillance programs. Great success was achieved during the enforcement period, and the number of malaria cases decreased by $65 \%$ during this period. Considering that some municipalities achieved very low levels of transmission, state forums raised the possibility of eliminating malaria in some regions. Some of the points that were discussed in this context included: 1) investment in the training of technicians and managers from the municipalities; 2) changing the definition of area stratification for disease control, surveillance, and elimination; 3) rational use of insecticides; and 4) investment in the use of LLINs to replace indoor spraying. Limited scientific evidence has provided support for the mass implementation of LLINs, justifying the need for further impact studies.

A quantitative improvement in the diagnostic network has been observed over the years. The network of laboratories for the diagnosis of malaria in Amazonas is the largest in the Brazilian Amazon, accounting for $33.7 \%(1,089 / 3,224)$ of the laboratories in the region ${ }^{(2)}$. The network expanded during the execution of PPACM and of a project financed by the Global Fund that also supported the employment and training of professionals. These measures, combined with the state's concern for the quality of diagnosis, helped Amazonas to achieve an excellent level of quality control and the diagnosis of malaria.

In Amazonas, the decrease in the incidence of falciparum malaria (Figure 5) and improvements in diagnosis over the years might be associated with the decreased occurrence of severe clinical cases of falciparum malaria and of syndromes such as tropical splenomegaly, which was frequently reported in areas of increased transmission of Plasmodium falciparum ${ }^{(27)}$. It is likely that the introduction of Coartem ${ }^{\circledR}$ in Manaus and other municipalities in its vicinity also contributed to the decrease in P. falciparum prevalence in the state. Conversely, an increase in the number of severe cases of Plasmodium vivax malaria was recently reported, which could be associated with the decompensation of acute and/or chronic comorbidities by malaria ${ }^{(28)(29)}$. Nevertheless, the overall fatality rate from malaria continues to decrease.

\section{Treatment}

Since the introduction of quinine, which for a long time was the only drug used for malaria treatment, major advances have been made in the treatment of malaria, primarily that caused by $P$. falciparum. With the introduction of chloroquine, 


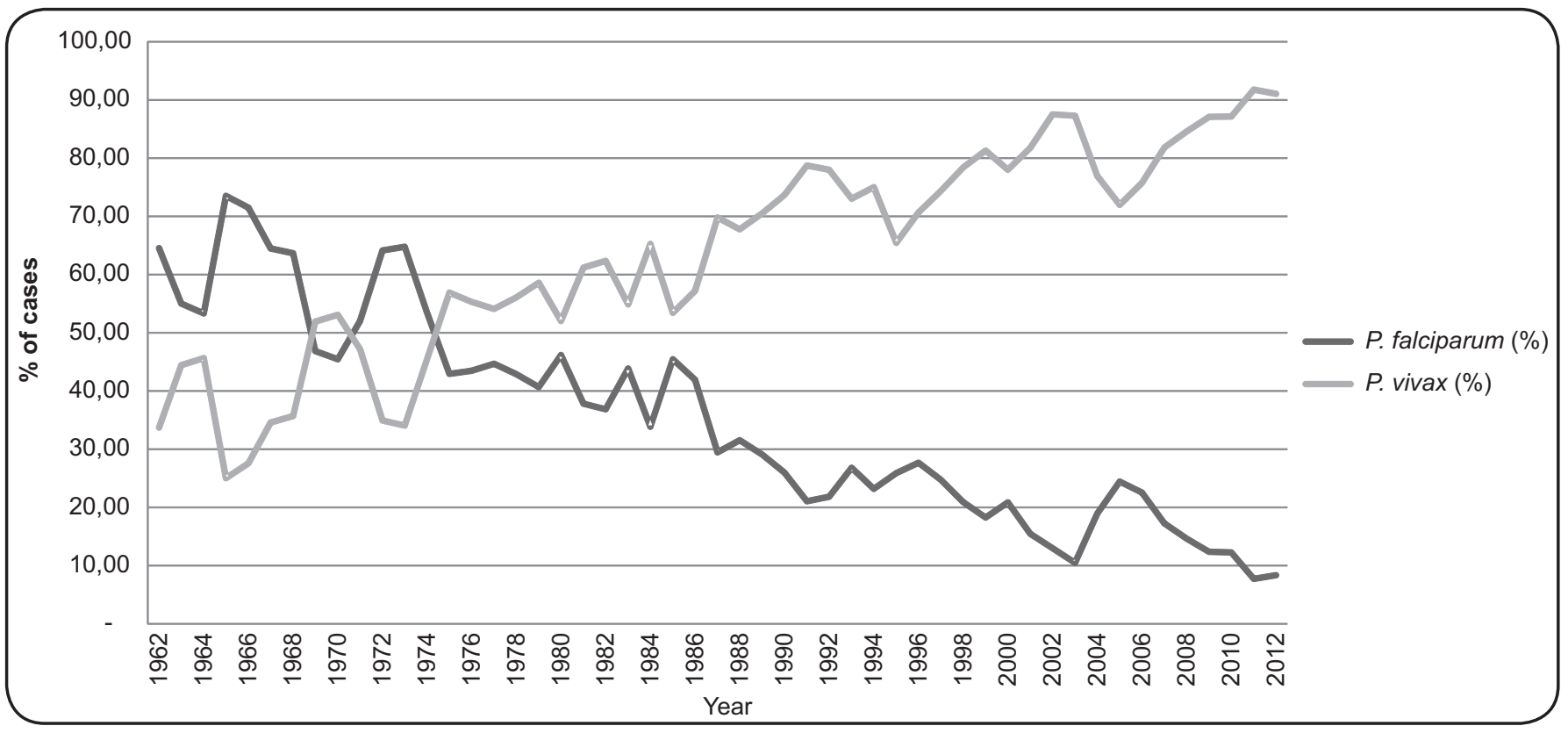

FIGURE 5 - Historical series of case percentages according to parasite species in the State of Amazonas between 1962 and 2012. P.: Plasmodium.

the first synthetic drug used in the treatment of this disease, malaria control gained an important tool. This drug was used indiscriminately throughout the second half of the $20^{\text {th }}$ century, and it was discontinued for the treatment of $P$. falciparum because of the high frequency of resistant parasite strains in the region ${ }^{(30)}$. One of the strategies aimed at the control of drug resistance was the Pinotti method, also known as the medicated salt method, which aimed to eliminate sources of infection via the addition of chloroquine to kitchen salt during the 1950s and $1960 \mathrm{~s}^{(31)}$.

By meeting the demands of state and municipal coordinating bodies and considering the growing number of studies reporting parasite resistance to antimalarial drugs, the Ministry of Health began to adopt mefloquine as the drug of choice for the treatment of $P$. falciparum malaria in the late 1980s. This strategy was maintained until the first half of the 2000s when the drug was replaced by the combination of artemether and lumefantrine ${ }^{(32)}$, and primaquine is also currently used. Mefloquine is still used in association with artesunate in the Extra-Amazon region ${ }^{(33)}$.

Some national studies have indicated the need for novel therapeutic strategies to circumvent the problem of chloroquine resistance for the treatment of $P$. vivax malaria, which is estimated at $5-10 \%$ in Manaus ${ }^{(34)}{ }^{(35)}$. It is possible that, in the short term, we may have to make use of artemisinin-based combination therapies (ACTs) as the first choice in the State of Amazonas, although other states have not reported cases of chloroquine resistance, which is expected in large areas such as the Brazilian Amazon. Concerned about this issue, the PNCM has supported studies conducted at FMT and the Research Center in Tropical Medicine [Centro de Pesquisa em Medicina Tropical (CEPEM)] in Porto Velho, Rondônia, where a combination of ACTs and primaquine is used for the treatment of $P$. vivax malaria. This parasite is also able to develop dormant stages (hypnozoites) in the liver, leading to frequent relapses. With the recent interest in malaria elimination in Brazil, P. vivax has become a significant challenge because no good tools are available to tackle hypnozoites and, therefore, relapses can occur ${ }^{(36)}$. Tafenoquine administered at a single dose of $300 \mathrm{mg}$ or $600 \mathrm{mg}$ has shown promising results in phase II studies ${ }^{(37)}$. However, potential hemolysis in patients with glucose-6-phosphate dehydrogenase deficiency (G6PDd) must be considered in the administration of this drug. In the State of Amazonas, G6PDd prevalence was estimated at $4.5 \%{ }^{(38)}$, and fatal cases have been reported among patients with vivax malaria treated with primaquine ${ }^{(28)}$. Introduction of tafenoquine as an anti-hypnozoite drug in the PNCM could be an important tool in the future goal of eliminating malaria, and tafenoquine use should stimulate the systematic screening of G6PDd using a rapid point-of-care testing system, although this screening still lacks accuracy and economical evaluation.

\section{CONCLUSIONS}

Despite the efforts of the campaigns and control programs implemented by the health care system, malaria continues to present major epidemiological challenges in Amazonas. Over time, there have been major changes in the epidemiological profile of malaria in the state, resulting in important historical moments for the economic and political situation in the state. Malaria on the rubber plantations was replaced by urban malaria in the ZFM in a process of epidemiological transition associated with the rural exodus and uncontrolled urbanization. Periods of economic growth, with consequent migratory flows, are considered the driving factors for malaria transmission. Therefore, for the effective control and eventual elimination of malaria in the state, health factors should be considered in all regional development projects. 


\section{CONFLICT OF INTEREST}

The authors declare that there is no conflict of interest.

\section{FINANCIAL SUPPORT}

This work was funded by the National Counsel of Technological and Scientific Development [Conselho Nacional de Desenvolvimento Científico e Tecnológico (CNPq)] and the Amazonas Research Foundation [Fundação de Amparo à Pesquisa do Estado do Amazonas (FAPEAM)].

\section{REFERENCES}

1. World Health Organization. World Malaria Report 2014. Geneva, Switzerland: WHO press; 2014.

2. Ministério da Saúde, Secretaria de Vigilância em Saúde. Boletim Epidemiológico de Malária (Internet). Brasília: Secretaria de Vigilância em Saúde. Ministério da Saúde; 2013. (Cited 2015 February 5). Available at: http://bvsms.saude.gov.br/bvs/periodicos/ boletim_epidemiologico_numero_1_2013.pdf/

3. Barros-Barreto J. Malária: doutrina e prática. Rio de Janeiro, RJ: Editora A Noite; 1940.

4. Langerwisch F, Rost S, Gerten D, Poulter B, Rammig A, Cramer W. Potential effects of climate change on inundation patterns in the Amazon Basin. Hydrol Earth Syst Sci 2013; 17:2247-2262.

5. Fearnside PM. The value of protected areas in avoiding climate change in Amazonia. Updating of priority areas for conservation, Sustainable use and sharing of the biodiversity Benefits-Amazon. Biome 2008; 2008: 8-11.

6. Santos UM, Bringel SRB, Filho HB, Ribeiro MNG, Bananeira M. Rios da Bacia Amazônica. I. Afluentes do Rio Negro. Acta Amaz 1984; 14:222-237.

7. Veríssimo A, Rolla A, Maior APCS, Monteiro A, Brito B, Souza C, et al. Áreas Protegidas na Amazônia Brasileira: avanços e desafios (Internet). 2011. (Cited 2015 October 1). Available at: http://www. imazon.org.br/publicacoes/livros/areas-protegidas-na-amazoniabrasileira-avancos-e-desafios

8. Tadei WP, Thatcher BD, Santos JM, Scarpassa VM, Rodrigues IB, Rafael MS. Ecologic observations on anopheline vectors of malaria in the Brazilian Amazon. Am J Trop Med Hyg 1998; 59:325-335.

9. Confalonieri UEC, Margonari C, Quintao AF, Quintão AF. Environmental Change and the dynamics of parasitic diseases in the Amazon. Acta Trop 2013; 129:33-41.

10. Grandin G. Fordlandia: the rise and fall of Henry Ford's forgotten jungle city. New York: Metropolitan Books; 2009.

11. Loureiro AJS. História da medicina e das doenças no Amazonas. Manaus: Lorena; 2004.

12. Batista D. O Complexo da Amazônia: análise do processo de desenvolvimento. Manaus: Valer; 1976.

13. Castro ARM, Sanjad N, Romeiro DS. Da pátria da seringueira à borracha de plantação: Jacques Huber e seus estudos sobre a cultura das heveas no Oriente (1911-1912). Bol Mus Para Emílio Goeldi Ciênc Hum 2009; 4:503-545.

14. Marques AC. Migrations and the dissemination of malaria in Brazil. Mem Inst Oswaldo Cruz 1986; 81:17-30.

15. Pinheiro FP, Bensabath G, Rosa APAT, Lainson R, Shaw JJ, Ward R, et al. Public Health Hazards Among Workers Along The TransAmazon Highway. J Occup Environ Med 1977; 19:490-497.
16. Marques AC, Pinheiro EA. Migration of cases of malaria in Brazil in 1980. Rev Bras Malariol Doencas Trop 1982; 34:1-31.

17. Saraiva M, Amorim RD, Moura MA, Martinez-Espinosa FE, Barbosa MG. Urban expansion and spatial distribution of malaria in the municipality of Manaus, State of Amazonas. Rev Soc Bras Med Trop 2009; 42:515-522.

18. Oliveira-Ferreira J, Lacerda MVG, Brasil PP, Ladislau JJLB, Tauil PL, Daniel-Ribeiro CCT. Malaria in Brazil: an overview. Malar J 2010; 9:115.

19. Albuquerque BC. Foco residual de malária na rodovia Manaus - Boa Vista (BR 174). (Master's Thesis). (Rio de Janeiro): Universidade Federal do Rio de Janeiro; 1982. 120 p.

20. Couto RCS. Malária: o custo social da Hidrelétrica de Tucuruí-PA, Brasil. In: Couto RCS, Castro EMR, Marin RA, editors. Saúde, Trabalho e Meio Ambiente: Políticas Públicas na Amazônia. Belém: Editora Universitária do Pará; 2002. p. 107-121.

21. Costa KM, Almeida WA, Magalhães IB, Montoya R, Moura MS, Lacerda MV. Malaria in Cruzeiro do Sul (Western Brazilian Amazon): analysis of the historical series from 1998 to 2008. Rev Panam Salud Publica 2010; 28:353-360.

22. Terrazas WCM. Desenvolvimento de SIG para análise epidemiológica da distribuição espacial da malaria no município de Manaus: um enfoque em nível local (Master's Thesis). (Rio de Janeiro): Escola Nacional de Saúde Pública Sergio Arouca; 2005. $107 \mathrm{p}$.

23. Ministério da Saúde. Sistema de Informação de Vigilância Epidemiológica de Malária (SIVEP) Malária (Internet). Brasília: Ministério da Saúde (Cited 2014 August 12). Available at: http:// www.saude.gov.br/malaria

24. Deane LM. Os grandes marcos na história do controle da malária. Rev Soc Bras Med Trop 1992; 25:12-22.

25. Ladislau JLB, Leal MC, Tauil PL. Avaliação do Plano de Intensificação das Ações de controle da malária na região da Amazônia Legal, Brasil, no contexto da descentralização. Epidemiol Serviços Saude 2006; 15:9-20.

26. Secretaria de Estado de Saúde do Amazonas. Resolução CIB 059/2011 que dispõe sobre a revisão do desenho regional do estado do Amazonas para a saúde. Manaus: Secretaria de Estado de Saúde do Amazonas; 2011.

27. Alecrim WD. Estudo clínico-epidemiológico da malária no Rio Ituxi-Amazonas (Master's Thesis). (Brasília): Universidade de Brasília; 1979. $115 \mathrm{p}$.

28. Lacerda MV, Mourão MP, Alexandre MA, Siqueira AM, Magalhães BM, Martinez-Espinosa FE, et al. Understanding the clinical spectrum of complicated Plasmodium vivax malaria: a systematic review on the contributions of the Brazilian literature. Malar J 2012; 11:12.

29. Santos-Ciminera PD, Roberts DR, Alecrim M, Costa MR, Quinnan Jr. GV. Malaria diagnosis and hospitalization trends, Brazil. Emerg Infect Dis 2007; 13:1597-1600.

30. Vieira PP, Ferreira MU, Alecrim M, Alecrim WD, Silva LH, Sihuincha MM, et al. pfert Polymorphism and the spread of chloroquine resistance in Plasmodium falciparum populations across the Amazon Basin. J Infect Dis 2004;190:417-424.

31. Pinotti M. New method of malaria prevention: combination of an antimalarial drug with table salt used daily in food. Rev Bras Malariol Doencas Trop 1954; 6:5-12.

32. Alecrim MG, Lacerda MV, Mourao MP, Alecrim WD, Padilha A, Cardoso BS, et al. Successful treatment of Plasmodium falciparum malaria with a six-dose regimen of artemether-lumefantrine versus quinine-doxycycline in the Western Amazon region of Brazil. Am J Trop Med Hyg 2006; 74:20-25. 
33. Ministério da Saúde. Guia prático de tratamento da malária no Brasil. Brasília: Ministério da Saúde; 2010.

34. Alecrim MGC, Alecrim W, Macêdo V. Plasmodium vivax resistance to chloroquine (R2) and mefloquine (R3) in Brazilian Amazon region. Rev Soc Bras Med Trop 1999; 32:67-68.

35. Santana-Filho FS, Arcanjo ARL, Chehuan YM, Costa MR, MartinezEspinosa FE, Vieira JL, et al. Chloroquine-resistant Plasmodium vivax, Brazilian Amazon. Emerg Infect Dis 2007; 13:1125-1126.

36. Wells TNC, Burrows JN, Baird JK. Targeting the hypnozoite reservoir of Plasmodium vivax: the hidden obstacle to malaria elimination. Trends Parasitol 2010; 26:145-151.
37. Llanos-Cuentas A, Lacerda MV, Rueangweerayut R, Krudsood S, Gupta SK, Kochar SK, et al. Tafenoquine plus chloroquine for the treatment and relapse prevention of Plasmodium vivax malaria (DETECTIVE): a multicentre, double-blind, randomised, phase $2 \mathrm{~b}$ dose-selection study. Lancet 2014; 383:1049-1058.

38. Santana MS, Monteiro WM, Siqueira AM, Costa MF, Sampaio V, Lacerda MV, et al. Glucose-6-phosphate dehydrogenase deficient variants are associated with reduced susceptibility to malaria in the Brazilian Amazon. Trans R Soc Trop Med Hyg 2013; 107: 301-306. 